\title{
Relative effects of response contingent pre-time-out and pre-food stimuli upon operant responding
}

HARLYN D. HAMM ${ }^{2}$ and JOSEPH ZIMMERMAN, Indiana University Medical Center, Indianapolis, Ind. 46207

Responding on each of two keys produced grain or time-out. The relative reinforcing properties of pre-grain and pre-time-out stimuli were compared. Under the conditions of this experiment the pre-food stimuli functioned as positive reinforcers while pre-time-out stimuli did not function as negative reinforcers.

As employed in most operant studies, time out (TO) is a period during which the scheduled presentation of a positive reinforcer is discontinued. Morse \& Herrnstein (1956) and Thomas (1965) demonstrated that under conditions in which pecking one key intermittently produced grain; pigeons would peck a second key when such responses postponed TO. These results appeared to have demonstrated that TO is an aversive event.

Leitenberg (1965) has pointed out, however, that although it is possible that "avoidance responding in these studies is maintained primarily because it postpones an aversive event-TO from positive reinforcement, it could be said that these studies only indicate that Ss will maintain behavior which leads to positive reinforcement." Indeed, in these studies grain frequency was maximized by responding on an avoidance key. Leitenberg indicated that "consequently what would be more convincing is a demonstration that Ss will learn to avoid stimuli which previously set the occasion for TO from positive reinforcement."

As suggested by Leitenberg, the present study attempted to assess the aversive properties of a stimulus which set the occasion for TO. We did so by comparing the reinforcing properties of a set of pre-TO (PTO) stimuli with the reinforcing properties of a set of stimuli which set the occasion for grain presentation, i.e., a set of pre-food (PF) stimuli.

\section{METHOD}

Four White Carneaux pigeons were maintained at $80 \%$ of their free feeding weight and were run daily in a standard two-key experimental space. Ss were shaped to peck each of two white keys and then placed on concurrent VI 2, VI 2 schedules of grain reinforcement. That is, pecking on each key independently produced access to grain on an average of once each $2 \mathrm{~min}$. The VI
2, VI 2 schedules were replaced after seven sessions by a single schedule (VI 3) which set up programmed events simultaneously on both keys, on the average of once each $3 \mathrm{~min}$. A peck on either key produced the programmed event. Half of these events were 5 -sec grain presentations while the rest were 2-min TOs. During TO, the house and key lights were extinguished. Grain and TO were presented in random order. Each TO and each grain presentation was preceded by a 0.5 -sec period during which prevailing stimuli (white noise and white key lights) were replaced with other stimuli. During the 0.5 -sec PTO-stimulus period, a red light was projected on the key and a $5000 \mathrm{cps}$ tone was presented. During the 0.5-sec PF-stimulus period, a green light was projected on the key and a $500 \mathrm{cps}$ tone was presented. Behavior generated under the above conditions served as a baseline against which we subsequently compared and assessed the reinforcing function of the two sets of $0.5-\sec$ stimuli.

Table 1 orders the conditions to which each of the Ss were exposed over the course of the investigation. After Ss were exposed to 24 sessions under the above conditions (Baseline ${ }_{1}$ ) we assessed the reinforcing properties of the two sets of $0.5-\mathrm{sec}$ stimuli by superimposing a VI 1 schedule of PTO stimuli on one key while superimposing an independent VI 1 schedule of PF stimuli on the other key. A delay contingency on each key insured that delivery of grain or TO was separated by at least $5 \mathrm{sec}$ from the delivery of extra PF or PTO stimuli. Each S was exposed to these conditions for from one to three sessions, and then exposed for another one to three sessions under similar conditions except that the key locations of the superimposed extra stimuli were reversed. The Ss were then exposed to 48 sessions in which baseline conditions were reinstated, but in order to assess the possible contribution of stimulus preference, per se, the stimuli associated with grain and TO were reversed. Behavior generated under these (Baseline ${ }_{2}$ ) conditions, were subsequently employed to assess the effects of further extra-stimulus probes. Table 1 shows that we first repeated the initial set of probes and subsequently ran probes involving the superimposition of the PTO stimuli only and later the superimposition of the PF stimuli only. RESULTS

Figure 1 presents a summary of results in terms of per cent

Table 1

Order of the Baseline and Probe Conditions to Which Each Bird was Exposed

\begin{tabular}{|c|c|c|c|c|c|c|c|c|c|c|c|c|}
\hline \multirow[b]{2}{*}{ Cond. } & \multicolumn{3}{|c|}{ Bird No. 70} & \multicolumn{3}{|c|}{ Bird No. 23} & \multicolumn{3}{|c|}{ Bird No. 24} & \multicolumn{3}{|c|}{ Bird No. 25} \\
\hline & $\begin{array}{l}\text { L. } \\
\text { Key }\end{array}$ & $\begin{array}{c}\text { R. } \\
\text { Key }\end{array}$ & $\begin{array}{l}\text { No. of } \\
\text { Sess. }\end{array}$ & $\begin{array}{c}\text { L. } \\
\text { Key }\end{array}$ & $\begin{array}{c}\text { R. } \\
\text { Key }\end{array}$ & $\begin{array}{l}\text { No. of } \\
\text { Sess. }\end{array}$ & $\begin{array}{c}\text { L. } \\
\text { Key }\end{array}$ & $\begin{array}{l}\text { R. } \\
\text { Key }\end{array}$ & $\begin{array}{l}\text { No. of } \\
\text { Sess. }\end{array}$ & $\begin{array}{l}\text { L. } \\
\text { Key }\end{array}$ & $\begin{array}{l}\text { R. } \\
\text { Key }\end{array}$ & $\begin{array}{l}\text { No. of } \\
\text { Sess. }\end{array}$ \\
\hline $\mathrm{BL}_{\mathbf{1}}$ & & & 24 & & & 24 & & & 24 & & & 24 \\
\hline $\begin{array}{l}\text { PF } \\
\text { vs PTO } \\
\end{array}$ & $\begin{array}{c}\text { PF } \\
\text { PTO } \\
\end{array}$ & $\begin{array}{c}\text { PTO } \\
\text { PF } \\
\end{array}$ & $\begin{array}{l}3 \\
1 \\
\end{array}$ & $\begin{array}{c}\text { PTO } \\
\text { PF }\end{array}$ & $\begin{array}{r}\text { PF } \\
\text { PTO } \\
\end{array}$ & $\begin{array}{l}3 \\
3 \\
\end{array}$ & $\begin{array}{c}\text { PTO } \\
\text { PF } \\
\end{array}$ & $\begin{array}{r}\text { PF } \\
\text { PTO }\end{array}$ & $\begin{array}{l}1 \\
3 \\
\end{array}$ & $\begin{array}{c}\text { PTO } \\
\text { PF }\end{array}$ & $\begin{array}{c}\text { PF } \\
\text { PTO }\end{array}$ & $\begin{array}{l}1 \\
1 \\
\end{array}$ \\
\hline $\mathrm{BL}_{2}{ }^{*}$ & & & 48 & & & 48 & & & 48 & & & 48 \\
\hline $\begin{array}{l}\text { PF } \\
\text { vs } \\
\text { PTO }\end{array}$ & $\begin{array}{r}\text { PF } \\
\text { PTO } \\
\text { PF } \\
\text { PTO } \\
\end{array}$ & $\begin{array}{c}\text { PTO } \\
\text { PF } \\
\text { PTO } \\
\text { PF }\end{array}$ & $\begin{array}{l}1 \\
1 \\
1 \\
1 \\
\end{array}$ & $\begin{array}{c}\text { PTO } \\
\text { PF } \\
\text { PTO } \\
\text { PF }\end{array}$ & $\begin{array}{r}\text { PF } \\
\text { PTO } \\
\text { PF } \\
\text { PTO }\end{array}$ & $\begin{array}{l}1 \\
1 \\
1 \\
1 \\
\end{array}$ & $\begin{array}{c}\text { PTO } \\
\text { PF } \\
\text { PTO } \\
\text { PF }\end{array}$ & $\begin{array}{c}\text { PF } \\
\text { PTO } \\
\text { PF } \\
\text { PTO } \\
\end{array}$ & $\begin{array}{l}1 \\
1 \\
1 \\
1\end{array}$ & $\begin{array}{c}\text { PF } \\
\text { PTO } \\
\text { PF } \\
\text { PTO }\end{array}$ & $\begin{array}{c}\text { PTO } \\
\text { PF } \\
\text { PTO } \\
\text { PF } \\
\end{array}$ & $\begin{array}{l}1 \\
1 \\
1 \\
1 \\
\end{array}$ \\
\hline $\mathrm{BL}_{2}$ & & & 7 & & & 7 & & & 7 & & & 7 \\
\hline $\begin{array}{l}\text { PTO } \\
\text { ONLY }\end{array}$ & $\begin{array}{l}\text { PTO } \\
\text { PTO } \\
\end{array}$ & $\begin{array}{l}\text { PTO } \\
\text { PTO }\end{array}$ & $\begin{array}{l}4 \\
4 \\
5 \\
6 \\
\end{array}$ & PTO & PTO & $\begin{array}{l}4 \\
6\end{array}$ & PTO & PTO & $\begin{array}{l}4 \\
6\end{array}$ & $\begin{array}{l}\text { PTO } \\
\text { PTO }\end{array}$ & PTO & $\begin{array}{r}4 \\
12\end{array}$ \\
\hline $\mathbf{B L}_{2}$ & & & 6 & & & 5 & & & 7 & & & 7 \\
\hline $\begin{array}{l}\text { PF } \\
\text { ONLY }\end{array}$ & $\begin{array}{l}\text { PF } \\
\text { PF }\end{array}$ & $\mathrm{PF}$ & $\begin{array}{l}2 \\
1 \\
4\end{array}$ & $\mathrm{PF}$ & $\begin{array}{l}\text { PF } \\
\text { PF }\end{array}$ & $\begin{array}{r}2 \\
1 \\
10\end{array}$ & $\begin{array}{l}\text { PF } \\
\text { PF }\end{array}$ & $\mathrm{PF}$ & $\begin{array}{l}2 \\
1 \\
9\end{array}$ & $\mathbf{P F}$ & $\begin{array}{l}\text { PF } \\
\text { PF }\end{array}$ & $\begin{array}{l}2 \\
1 \\
5\end{array}$ \\
\hline
\end{tabular}

BL-Baseline, * Stimuli associated with grain and TO reversed. 


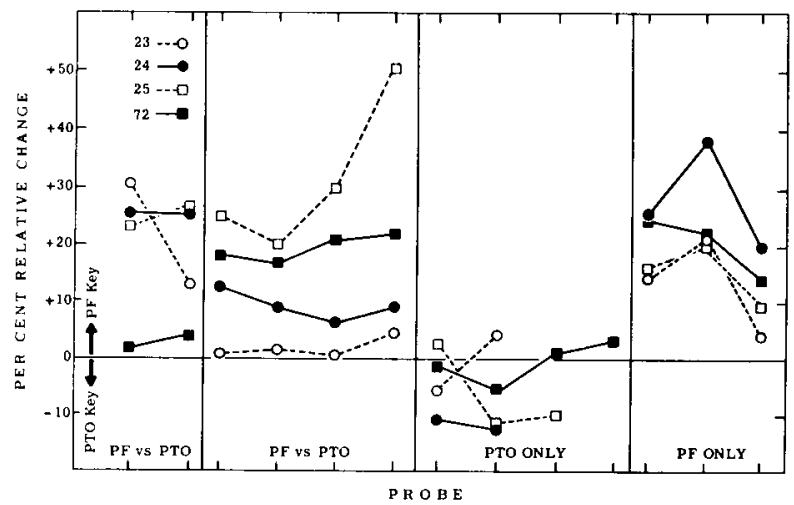

Fig. 1. Per cent change in relative responding to a given key as a function of the superimposition of the probe stimuli (PF and/or PTO) or reversal of key location of these superimposed stimuli.

change in relative responding to a given key as a function of the superimposition of the PTO and/or PF stimuli. Relative responding to a given key is defined as the number of responses to that key divided by the total number of responses. The vertical lines in Fig. 1 separate sets of probes. Within each set of probes the first abscissa mark denotes a change from baseline conditions to a probe and the remaining marks denote successive reversals of the PF and/or PTO-stimuli key locations. The plotted points present results obtained in the first session of each experimental probe. An ordinate deviation in the positive direction indicates a shift in relative responding away from the key upon which PTO stimuli were programmed and/or towards the key upon which the PF stimuli were programmed.

During the first set of experimental probes (PF vs PTO) both PTO and PF stimuli were presented. With the first probe three of four Ss showed a marked $(22-30 \%)$ shift in relative responding toward the key upon which the PF stimuli were programmed (PF key). Bird 72 shifted only slightly (2\%) toward the PF key. When the key location of the two sets of stimuli were reversed, three Ss again shifted markedly (12-26\%) toward the (new) PF key and Bird 72 again shifted slightly (now $4 \%$ ) to this key.

Following subsequent exposure of the Ss to 48 Baseline $_{2}$ sessions, PF vs PTO-stimuli probes were again programmed. Birds 25 and 72 demonstrated marked (17\% or greater) shifts in preference, both with the introduction of the first probe and with each successive key-location reversal of the two sets of stimuli.

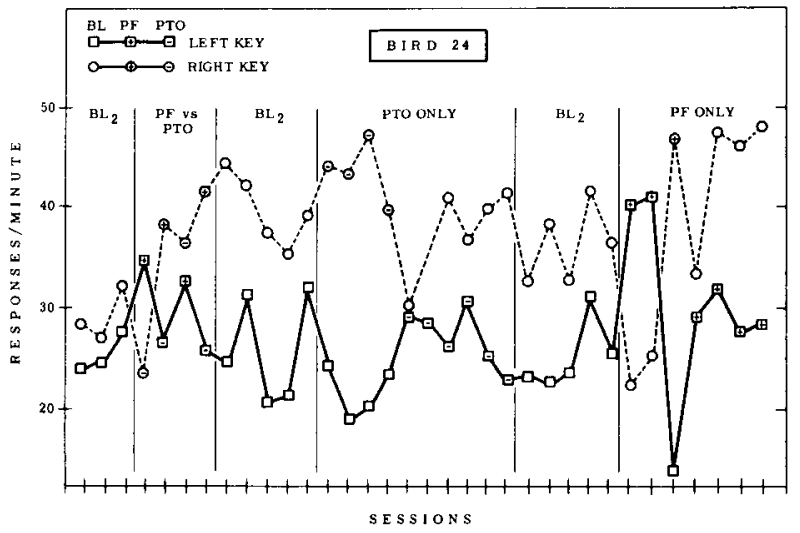

Fig. 2. Absolute rate of responding to the two keys for Bird 24 across daily sessions beginning with the last three sessions of the first Baseline ${ }_{2}\left(\mathrm{BL}_{2}\right)$ condition and ending with the first four sessions of the last probe (PF only).
Bird 24 slowed moderate shifts (7-12\%) while Bird 23 was either not influenced or showed slight (less than $5 \%$ ) shifts.

Following seven additional sessions of exposure to Baseline ${ }_{2}$ conditions, a set of PTO-only probes (extra PTO stimuli superimposed on one key) were run. None of the Ss showed a consistent tendency to shift away from the PTO key during these probes. The fact that most shifts obtained with this third series of probes were relatively small in magnitude compared to most shifts previously observed with the earlier probes suggested that the previous results might have been almost entirely accounted for on the basis of the positive conditioned reinforcing power of the PF stimuli. As a consequence, all Ss were subsequently exposed to from five to seven additional Baseline ${ }_{2}$ sessions and finally to a set of PF-only probes (extra PF stimuli superimposed on one key). The nature and magnitude of the shifts observed with these final probes were generally similar to those obtained with the two sets of PF vs PTO probes.

The changes in key preference reflected in the per cent relative responding to the two keys were generally apparent in the absolute rate of responding to the two keys. Figure 2 presents the absolute rate of responding to the two keys for Bird 24 over a continuous series of daily sessions beginning with the last three sessions of the first Baseline, ${ }_{2}$ condition and running through the first four sessions of the last probe condition. Vertical lines separate Baseline ${ }_{2}$ sessions from probe sessions. Figure 2 shows that rates of responding on the PF key generally increased, while rates on the PTO key generally decreased under the PF vs PTO probes and PF-only probes. The decrease in rates on the PTO key noted in the first probes (PTO vs PF) did not occur under the PTO-only probes. In fact, Bird 24 showed an increase in rate on the PTO key during the PTO-only probe. The data from the final probe in Fig. 2 (last four sessions) indicates that the magnitude of the key-preference shifts obtained in the first session diminished in the second session and then remained stable thereafter. Similar attenuation of the first session effect was occasionally noted over successive sessions of given probes with other Ss.

$$
\text { DISCUSSION }
$$

Stimuli associated with TO did not appear to function as aversive stimuli in the present situation. That key shifts observed with the first two sets of probes were controlled by the PF stimuli, per se, was supported by the results obtained with the last two sets of probes. While shifts observed with the PTO-only probes were neither consistent in direction nor large in magnitude, shifts observed in the PF-only probes were similar to those observed initially.

While we did not obtain evidence for aversive properties of PTO stimuli, the results obtained with the final set of probes suggest that the present procedure (or similar ones) might serve as an effective tool for assessing the positive reinforcing properties of pre-event stimuli.

The present experimental paradigm is a complex one in that it involves the response contingent programming of TO, grain, and extra PF and/or PTO stimuli. Present research is directed at simplifying the paradigm and determining of the response contingent scheduling of grain and TO may have overshadowed any subtle aversive aspects of the PTO stimuli.

\section{REFERENCES}

LEITENBERG, $\mathrm{H}$. Is time-out from positive reinforcement an aversive event. Psychological Bulletin, 1965, 64, 428-441.

MORSE, W. H., \& HERRNSTEIN, R. J. The maintenance of avoidance behavior using the removal of a conditioned positive reinforcer as the aversive stimulus. American Psychologist, 1956, 1 1, 430 (abstract).

THOMAS, J. R. Discriminated time-out avoidance in pigeons. Journal of the Experimental Analysis of Behavior, 8, 1965, 329-338. NOTES

1. This research was supported by U.S.P.H.S. grants MH 10741 and MS 10695 .

2. Now at Northern Michigan University, Marquette, Michigan. 